\title{
Exploring Social Media Use and Civic Engagement on the Discussion of
}

\section{Antinuclear Issue}

\author{
Cathy S. Lin ${ }^{1, *}$, Feng Yang Kuo ${ }^{2}$, Ching Ya Hung ${ }^{3}$ \\ ${ }^{1,3}$ National University of Kaohsiung, Taiwan \\ ${ }^{2}$ National Sun Yat-Sen University, Taiwan \\ ${ }^{1}$ cathy@nuk.edu.tw*; ${ }^{2}$ bkuo@mis.nsysu.edu.tw; ${ }^{3}$ sportbass805@gmail.com \\ * corresponding author
}

(Received: September 1, 2021; Revised: October 25, 2021; Accepted: November 15, 2021; Available online: December 16, 2021)

\begin{abstract}
Social media has brought a new communication revolution allowing users to connect, share, and discuss public \& social opinions with others. The new look at social media has shaped social movements, and provides a fair voice to anyone who can be heard online. This research explores individuals' civic engagement concerning the environmental issue of nuclear energy on social media. Nuclear energy is a global, social, and environmental issue, the research variables included in this study are self-presentation efficacy, fear of social isolation and stigma consciousness. The findings from this study will have implications for both research and practices, especially help understanding the civic engagement of social movement on social media.
\end{abstract}

Keywords: Social Media, Anti-Nuclear Energy, Self-Presentation Efficacy, Civic Engagement

\section{Introduction}

\subsection{Research Background}

According to an investigation into broadband usage in Taiwan, the two most frequent activities internet users participate nowadays are using social network services (64.31\%) and instant message software (51.45\%) [1]. Recently the usage of social network sites (SNSs) has gradually extended its scope from interpersonal interactions to establish connections in terms of interests, political views and activities among strangers [2]. According to a survey conducted by Pew Research Center's Internet \& American Life Project, 36\% of the SNS users recognize the importance of SNSs for their understandings of news and current events; $25 \%$ of the users recognize the importance of SNSs for discussing public issues with others also $25 \%$ of the users recognize the importance of SNSs for understanding the information of public issues shared by others [3].

\subsection{Motivation and Purposes}

Although SNSs possess the possibilities of spreading information in rapid speed and attracting the attention to public issues from the public for further discussion, the majority of users are not willing to show their standpoints in the controversial public issues, let alone expressing their opinions or discussing the public issues [4]. Civic engagement, being one of the cores in democracy, can promote the development of society. In this study, the factors which influence online users in the discussion about public issues will be explored. Public issues cover various topics such as cultural, economic, political, social and daily life issues [5].

Among those issues, the topic concerning nuclear power was chosen in this study since the debate on nuclear power has been a vital global environmental issue, and the voice about abolition of nuclear energy has become a stronger trend these years [6]. For example, the "Green citizens' action alliance", which is dedicated to establishing environmental policies in Taiwan and reminding the concern in various environmental conservation issues, provides 
various resources and information regarding nuclear energy [7]. There are other groups of anti-nuclear energy citizens creating fan clubs on Facebook, like "Non-Governmental Organization", "Mom Loves Taiwan - non-profit organization" and sharing the information related to NO nuclear energy as well as holding a series of opposition nuclear activities. Therefore, the utilization of social media enables people to develop their awareness of the nuclear energy issue and force the related governmental organizations to pay attention to the voice from ordinary people when making policies. This study aims at exploring the social related antecedents concerning affecting an individual's participation in the discussions of nuclear power on SNS.

\section{Literature Reviews}

\subsection{Civic Engagement}

Civic engagement has its importance in the development of a democratic society. The rise of the Internet not only provides knowledge and establishes connections to network users but also helps users increase the possibility of civic engagement. It also improves the imbalance of information that users who were engaging in the discussion of public issues would encounter in the past and therefore increases the capacity of civic engagement greatly. Gebre and Morales [8] consider the information oriented behaviors on the Internet, such as acquisition and exchange of information, can promote the degree of civic engagement from the Internet users. Besides, compared to the traditional media that are one-directional and non-multidimensional, the Internet provides articles and information for users to search, allows arguments from different positions so that users who care about public issues can view the issue from different points of view [9].

This study believes that the major civic engagements that Internet users can take are sharing information and exchanging opinions. Through participation in the discussion of public issues, an individual can promote the understanding of public affairs and also increase the inclination of participating in public affairs [10]. The ways of opinion discussion and expression in social media are not limited to text publication; it also includes sharing information, becoming a member of a certain fan page or club which is dedicated to a certain public issue on Facebook, approving and encouraging others when they share their opinions and information and taking further step to discuss the issues [11]. Thus, the way of expressing and discussing public issues in social media is one of the processes of civic engagement nowadays.

\subsection{Self-presentation Efficacy}

The concept of self-efficacy comes from Larkins et al [12], who proposes the social cognitive theory. In social cognitive theory, Bandura considers human behavior as a dynamic equilibrium system produced by personal, behavioral and environmental interactions. The core of this triangle interaction is self-efficacy. It represents the belief of an individual in himself/herself to execute a certain action in order to reach a certain goal [13]. This belief comes from the self-cognition which is formed by the past experience and evaluated by the social, cultural and body abilities as a whole.

In a study of civic engagement, political efficacy is used to evaluate the confidence level of an individual in the ability to influence public policy and participate in civic engagement activities. Pang [14], explore the role the political efficacy plays in the relation of Facebook usage and civic engagement and point out the interaction of political efficacy and Facebook usage will influence the civic engagement intention. In this study, self-expression efficacy is proposed based on an individual's political efficacy, to understand online user's confidence in his/her self-expression concerning nuclear power issues on social media [15].

H1: Individual's self-presentation efficacy will impact on the intention of nuclear energy discussion. 


\subsection{Fear of Social Isolation}

The concept of a fear of social isolation comes from the Spiral of Silence Theory proposed by Rafique et al. [16], In the Spiral of Silence Theory, it is pointed out that the intention of expressing personal opinions is influenced by the perceived atmosphere in the discussion. That is, an individual tends to have higher motivation to express personal opinions and thoughts publicly if the individual perceives the situation that his/her opinions are similar to those of majority and further obtains support from others. On the other hand, an individual tends not to express personal opinions if he or she perceives the situation in which his/her opinions are different from those of majority to avoid the potential threat of being isolated. As a result, the opinions taken as mainstream may become stronger and stronger whereas the opinions taken as minority may become weaker and weaker. Tangchonlatip et al. [17] points out that the fear of social isolation comes from the social desire of people so that people are afraid of being separated or isolated from others and expect to be respected or liked. In other words, people tend to decline to express personal opinions due to the fear of being isolated from the society when his or her position belongs to a vulnerable group.

The fear of being socially isolated may influence people in perceiving the opinion atmosphere in a situation of public issue discussion, it also influences the choice and judgment an individual may make on the position of public issues. The higher the fear an individual has, the less possibility for the individual to express personal opinions when the individual has different opinions in an opinion atmosphere in a situation. H2: Individual's fear of social isolation will impact on the intention of nuclear energy discussion.

\subsection{Stigma Consciousness}

Ky Vien [18] proposes the concept of sigma-consciousness, which refers to the degree of cognition an individual has regarding being treated under stereotype. It has an important influence on the way the individual deals with the status of mistreatment under stereotype. An individual with sigma-consciousness has connected himself/herself with the belief of being stigma and internalized it as a part of self-concept. Wilkin [19] points out that the behaviors of public issue discussion may be affected by race discrimination so that the ones who suffer discrimination may choose silence to avoid being attacked which leads to one-sided opinions. In the study, we posit that an individual may be affected by stigma consciousness in on-line discussion and incline to avoid being trapped into a situation in which being treated under stigma.

H3: Individual's stigma consciousness will impact on the intention to nuclear energy discussion

\section{Methodologies}

\subsection{Scenario Design}

A scenario-based vignette and a field survey are concurrently adopted for conducting the present study. Vignettes have the advantages of providing a less-intimidating way to respond to sensitive issues and offering realistic scenarios that place the subject in a decision-making role [20]. In this study, to reflect the sensitive nature of public issues, it is appropriate to adopt the design of the scenario-based vignette in this study.

The background context describes the opposition to nuclear energy, which indicates that the problem of radiation may cause severe and long-term damage to people and ecology. The scenario arguments are designed in accordance with most user's opinions on Facebook, that is, antinuclear is the mainstream opinion on Facebook [21]. Therefore, this study adopts an anti-nuclear issue as the research situation, so as to explore the personal factors of self-presentation efficacy, and social factors of fear of social isolation and stigma consciousness may affect in the participation of on-line public issue discussion in the online nuclear energy issue discussion.

\subsection{Measurement Items}

The survey instruments comprises four research constructs, they are self-presentation efficacy, fear of social isolation, stigma consciousness, and intention to anti-nuclear energy discussion. The measurement items came from the 
previous studies to ensure content validity. All items used seven-point Likert scales anchored from strongly disagree $(=1)$ to strongly agree $(=7)$.

\subsection{Research Subjects}

The empirical data were collected by conducting an online survey in Taiwan. According to a survey of "analysis of the current usage of social media" conducted by the Market Intelligence \& Consulting Institute of Institute for Information Industry, it shows that the most used social media by Taiwanese on-line users is Facebook (95.8\% of usage). Facebook not only is the most used social networking site but also the most widespread platform for user's participation in public issue discussion. Therefore, the objects of this study are Facebook users.

\section{Data Analysis}

\subsection{Sample Demographics}

In this study, the scenario based survey is conducted to collect data from the related antinuclear energy fan club pages on Facebook. The online survey received 194 usable responses. Of the survey respondents, 96 (49.5\%) were male and $98(50.5 \%)$ were female. The details of demographic statistics information are shown in Table 1.

Table. 2. Demographic Statistics

\begin{tabular}{|c|c|c|c|}
\hline \multirow{2}{*}{ Demographic Variables } & \multicolumn{3}{|c|}{ Sample (N=194) } \\
\cline { 2 - 4 } & \multicolumn{2}{|c|}{ Mean } & SD \\
\hline Age (years) & \multicolumn{2}{|c|}{25.66} & 6.66 \\
\hline Internet experience (years) & \multicolumn{2}{|c|}{11.60} & 3.53 \\
\hline \multirow{2}{*}{ Gender } & Category & Freq. & $\%$ \\
\hline & Male & 96 & $49.5 \%$ \\
\cline { 2 - 4 } & Female & 98 & $50.5 \%$ \\
\hline
\end{tabular}

\subsection{Reliability and Validity}

To assess convergent and discriminant validity, exploratory factor analyses were conducted to detect high loadings on factors, factor loadings values fall between 0.775- 0.924. All factor loadings are greater than 0.5 and all are statistically significant at $\mathrm{p}<0.01$. This implies that the measures satisfy convergent validity. All eigenvalues associated with the factors exceeding the level of 1, vary from 1.200 to 6.742 . Principal components analysis was used as the extraction method for factor analysis with Varimax rotation. As shown in Table 2, the overall factor structural solution has an appropriate loading pattern and explains 79.531 percent of the variation. Therefore, convergent and discriminant validity are supported.

Table. 2. EFA for research constructs

\begin{tabular}{|c|c|c|c|c|c|c|c|}
\hline \multirow[t]{2}{*}{ Constructs } & \multirow[t]{2}{*}{ Item } & \multicolumn{4}{|c|}{ Factor Loading } & \multirow[t]{2}{*}{ Eigenvalues } & \multirow{2}{*}{$\begin{array}{c}\text { Sums of } \\
\text { Squared } \\
\text { Loadings }\end{array}$} \\
\hline & & 1 & 2 & 3 & 4 & & \\
\hline Self- & 5 & -0.077 & 0.788 & 0.252 & -0.063 & 4.245 & 61.035 \\
\hline
\end{tabular}




\begin{tabular}{|c|c|c|c|c|c|c|c|}
\hline \multirow{4}{*}{$\begin{array}{l}\text { presentation } \\
\text { Efficacy }\end{array}$} & & -0.094 & 0.860 & 0.210 & -0.027 & & \\
\hline & & -0.052 & 0.890 & 0.184 & -0.045 & & \\
\hline & & -0.047 & 0.905 & 0.141 & -0.009 & & \\
\hline & & -0.010 & 0.833 & 0.110 & -0.009 & & \\
\hline \multirow{4}{*}{$\begin{array}{l}\text { Intention to } \\
\text { Nuclear Energy } \\
\text { Discussion }\end{array}$} & \multirow[t]{4}{*}{4} & -0.060 & 0.219 & 0.914 & -0.021 & \multirow[t]{4}{*}{2.129} & \multirow[t]{4}{*}{72.864} \\
\hline & & -0.098 & 0.205 & 0.920 & -0.096 & & \\
\hline & & -0.121 & 0.242 & 0.920 & -0.051 & & \\
\hline & & -0.125 & & 0.903 & -0.081 & & \\
\hline \multirow{3}{*}{$\begin{array}{c}\text { Stigma } \\
\text { Consciousness }\end{array}$} & \multirow[t]{3}{*}{3} & 0.259 & -0.041 & -0.005 & 0.777 & \multirow[t]{3}{*}{1.200} & \multirow[t]{3}{*}{79.531} \\
\hline & & 0.424 & -0.048 & -0.121 & 0.789 & & \\
\hline & & 0.311 & -0.026 & -0.114 & 0.835 & & \\
\hline
\end{tabular}

After the factor analysis, a reliability test was performed for the extracted factors. Table 3 demonstrates the descriptive statistics, reliabilities and correlation matrix among the research variables for the pros and cons nuclear energy scenarios. The reliability of each multiple-item measure is estimated using Cronbach's alpha, a commonly used measure of internal consistency. The alpha values fall between 0.842-0.964, these factors provide a reliable dimension.

Table .3. Descriptive statistics and Correlations for research constructs

\begin{tabular}{|l|l|l|l|l|l|l|l|}
\hline Constructs & Mean & STD & $\alpha$ & SE & FOI & StigC & INT \\
\hline SE & 4.771 & 1.371 & 0.923 & 1 & & & \\
\hline FOSI & 4.289 & 1.444 & 0.930 & $-.0150^{*}$ & 1 & & \\
\hline StigC & 3.806 & 1.334 & 40.842 & -0.116 & $0.595^{* *}$ & 1 & \\
\hline NT & 4.552 & 1.527 & 0.964 & $0.428^{* *}$ & $-0.227^{* *}$ & $-0.198^{*}$ & 1 \\
\hline $\begin{array}{l}* p<0.05 ; * * p<0.01 ~ 2 . \\
\text { SE=Self-presentation Efficacy, FOI=Fear of Social Isolation, } \\
\text { StigC=Stigma Consciousness, INT= Intention to Nuclear energy discussion }\end{array}$ & & & \\
\hline
\end{tabular}

\subsection{Model Validation}

To test the three hypotheses, this study assessed the proposed research model by using structural equation modeling (SEM). We chose SmartPLS 2.0.M3 for this analysis because PLS employs a component-based approach for 
estimation purposes and can handle second order latent variables. As recommended by Lin [22], bootstrapping with 500 subsamples was performed to test the statistical significance of each path coefficient using the t-test [23].

Figure 1 shows the results of the PLS analysis for the proposed research model. For the anti-nuclear energy vignette, self-presentation efficacy and fear of social isolation predict the dependent variable of intention are significant, with $\mathrm{R} 2=23.3 \%$. Observing the path coefficient of the three antecedents, self-presentation efficacy $(B=0.401, p<0.01)$ has positive and most dominant impact on the intention toward issue discussion. The fear of social isolation $(\beta=$ $-0.154, \mathrm{p}<0.05)$ has a significant negative impact on the intention toward issue discussion, yet the stigma consciousness has no significant impact $(\beta=-0.074)$ on the dependent variable.

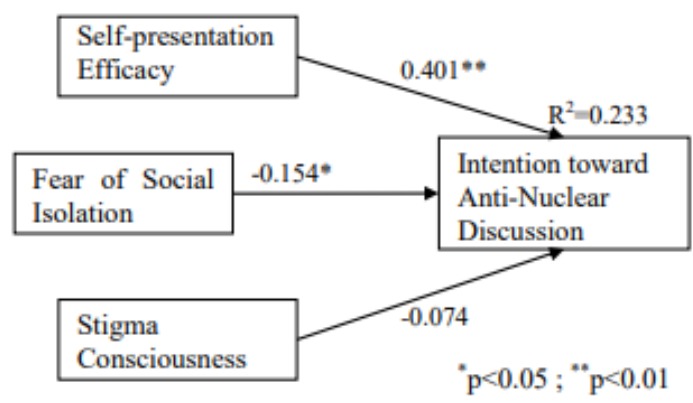

Figure. 1. Model Validation Results

\section{Conclusion}

The model validation results show that the personal factor of self-presentation efficacy is a dominant antecedent in predicting individuals' intention to discuss anti-nuclear energy on social networking sites. As for the important findings about the social factors, fear of social isolation will significantly negatively decrease user's intention toward public issue discussion. That is, when an individual perceives the higher perception about fear of social isolation, which will break one's intention to speak out. Understanding both the personal factor of self-presentation efficacy and the social factor about fear of isolation will contribute to academic and practitioners a closer look in understanding how the social networking site facilitates and/or impedes the public issue discussion online.

\section{References}

[1] V. Lesma, "Effect of Textual Errors on The Evaluation of a Foreign Online Store," IJIIS Int. J. Informatics Inf. Syst., vol. 3, no. 3, pp. 121-127, 2020, doi: 10.47738/ijiis.v3i1.95.

[2] A. Amini Sedeh, H. Abootorabi, and J. Zhang, "National social capital, perceived entrepreneurial ability and entrepreneurial intentions," Int. J. Entrep. Behav. Res., vol. 27, no. 2, pp. 334-355, 2021, doi: 10.1108/IJEBR-10-2019-0616.

[3] A. G. Andrei, A. Zait, C. Stoian, O. Tugulea, and A. Manolica, "Citizen engagement in the 'post-truth era': A knowledge management inquiry into the online spread of information," Kybernetes, vol. 49, no. 5, pp. 1429-1443, 2020, doi: 10.1108/K-03-2019-0178.

[4] C. Rabin and G. Smith, "Social Studies Research and Practice Article information :," Emeraldinsight, vol. 12, no. 3, pp. 325-340, 2017.

[5] B. Lori, "An internet utopia? Government use of web technologies to engage citizens in the US," Eletronic Libr., vol. 34, no. 1, pp. 1-5, 2018.

[6] A. Brunvand, "Researching Bears Ears: reference practice for civic engagement," Ref. Serv. Rev., vol. 48, no. 1, pp. 49-61, 2020, doi: 10.1108/RSR-09-2019-0061. 
[7] V. Marino and L. L. Presti, "Increasing convergence of civic engagement in management: a systematic literature review," Int. J. Public Sect. Manag., vol. 32, no. 3, pp. 282-301, 2019, doi: 10.1108/IJPSM-03-2018-0068.

[8] E. H. Gebre and E. Morales, "How 'accessible' is open data?: Analysis of context-related information and users' comments in open datasets," Inf. Learn. Sci., vol. 121, no. 1-2, pp. 19-36, 2020, doi: 10.1108/ILS-08-2019-0086.

[9] M. K. Heath, "What kind of (digital) citizen?: A between-studies analysis of research and teaching for democracy,” Int. J. Inf. Learn. Technol., vol. 35, no. 5, pp. 342-356, 2018, doi: 10.1108/IJILT-06-2018-0067.

[10] E. L. Hollander, "Civic education in research universities: Leaders or followers?," Educ. Train., vol. 53, no. 2, pp. 166-176, 2011, doi: 10.1108/00400911111115708.

[11] M. Huda, K. S. M. Teh, N. H. N. Muhammad, and B. M. Nasir, "Transmitting leadership based civic responsibility: insights from service learning,” Int. J. Ethics Syst., vol. 34, no. 1, pp. 20-31, 2018, doi: 10.1108/IJOES-05-2017-0079.

[12] M. Larkins, W. Wright, and S. Dann, "Sustainability and engagement: strange bedfellows in the undergraduate textbook,” Int. J. Sustain. High. Educ., vol. 19, no. 6, pp. 1053-1074, 2018, doi: 10.1108/IJSHE-09-2017-0152.

[13] O. Ojedokun, "Associations of the five-factor personality traits with environmental citizenship behavior of youth in a Nigerian university community," Manag. Environ. Qual. An Int. J., vol. 29, no. 6, pp. 1135-1155, 2018, doi: 10.1108/MEQ-02-2018-0040.

[14]H. Pang, "Can microblogs motivate involvement in civic and political life? Examining uses, gratifications and social outcomes among Chinese youth," Online Inf. Rev., vol. 42, no. 5, pp. 663-680, 2018, doi: 10.1108/OIR-04-2017-0136.

[15]D. V. Polanska and G. Chimiak, "Organizing without organizations: on informal social activism in Poland," Int. J. Sociol. Soc. Policy, vol. 36, no. 9-10, pp. 662-679, 2016, doi: 10.1108/IJSSP-11-2015-0120.

[16]Z. Rafique, S. L. Khoo, and M. W. Idrees, "Civic engagement among the youth: empirical evidence from Kashmir, Pakistan,” Humanomics, vol. 32, no. 3, pp. 376-388, 2016, doi: 10.1108/H-12-2015-0077.

[17] K. Tangchonlatip, A. Chamratrithirong, and A. Lucktong, "The potential for civic engagement of older persons in the ageing society of Thailand," J. Heal. Res., vol. 33, no. 5, pp. 386-397, 2019, doi: 10.1108/JHR-08-2018-0083.

[18]N. Ky Vien, "Modelling The Relationship of Perceived Quality, Destination Image, And Tourist Satisfaction at The Destination Level,” Int. J. Appl. Inf. Manag., vol. 1, no. 4, pp. 165-172, 2021, doi: 10.47738/ijaim.v1i4.18.

[19] C. Wilkin, "Education + Training Article information : learning perspective," Educ. + Train., vol. 57, no. 5, pp. 492-511, 2015.

[20] A. B. Wodika and W. K. Middleton, "Climate change advocacy: exploring links between student empowerment and civic engagement," Int. J. Sustain. High. Educ., vol. 21, no. 6, pp. 1209-1231, 2020, doi: 10.1108/IJSHE-03-2020-0091.

[21]A. Sulhi, "Data Mining Technology Used in an Internet of Things-Based Decision Support System for Information Processing Intelligent Manufacturing,” IJIIS Int. J. Informatics Inf. Syst., vol. 4, no. 3, pp. 168-179, 2021.

[22] S. Lin, "Investigate the Influence and Moderators of the Embarrassment on the Continual Usage and Knowledge Sharing Intention in Virtual Communities,” IJIIS Int. J. Informatics Inf. Syst., vol. 4, no. 3, pp. 180-191, 2021.

[23]T. Alvarez, "Meta-Analysis of Social Networking Sites for the Purpose of Preventing Privacy Threats in the Digital Age,” J. Appl. Data Sci., vol. 2, no. 3, pp. 64-73, 2021. 